Arq. Bras. Med. Vet. Zootec., v.63, n.2, p.508-510, 2011

\title{
Comunicação
}

[Communication]

\section{Potencial mirmecológico na vetoração mecânica de helmintos em gatis}

\author{
[Myrmecological potential in mechanic vectoring of helminthes in cats rescue center]
}

\author{
J.C. Machado ${ }^{1}$, M.S. Brugger ${ }^{2}$, J.O.T. Souza ${ }^{3}$, J.F.S. Lopes ${ }^{1}$
}

1Universidade Federal de Juiz de Fora - UFJF) - Juiz de Fora, MG

${ }^{2}$ Universidade Estadual Paulista "Julio Mesquita Filho" - UNESP - Botucatu, SP.

3Universidade Federal de Juiz de Fora - UFJF - Instituto de Ciências Biológicas - Juiz de Fora, MG.

Artrópodes, em especial os insetos, têm um papel interessante na vetoração de parasitos devido à sua ampla distribuição em diferentes habitats bem como seus hábitos alimentares. Thyssen et al. (2004) levantaram as espécies de helmintos presentes em três ordens de insetos que convivem próximo ao ambiente humano e avaliaram o papel dos indivíduos das ordens Blattodea, Diptera e Hymenoptera na vetoração mecânica de ovos de Oxyuridae, Ascaridae, Toxocaridae e Cestoda, bem como larvas de nematoda. Concluíram que os blatódeos são os principais vetores de tais parasitos. Outros autores ainda destacaram a importância dessa ordem na vetoração de bactérias como Salmonella enteritidis (Ash e Greenberg, 1980) e Helicobacter pylori (Imamura et al., 2003) e fungos (Fotedar e Banerjee, 1992).

A literatura revela a grande participação dos dípteros na vetoração de parasitos graças à sua intensa relação com o ambiente urbano. Helmintos como Toxocara sp., Ascaris sp. e Toxascaris sp. são alguns dos relatados na vetoração por dípteros (Oliveira et al., 2002).

Quantos aos Himenópteros, embora a discussão ainda seja tímida, o maior enfoque tem sido dado às formigas. Esses são relatados como insetos de importância na vetoração mecânica de parasitos, em especial ovos de helmintos, principalmente em hospitais (Zarzuella et al., 2002) e áreas de alimentação (Schüller, 2004). Um vetor mecânico usualmente contamina-se ao entrar em contato com material infectado, transportando parasitos para o ambiente ou para o alimento. A importância das formigas nesse tipo de vetoração pode relacionar-se à sua ampla distribuição e capacidade de adaptação a ambientes urbanos bem como ao hábito de forrageamento a longas distâncias, o que permite que acessem esgotos, lixos e outros locais contaminados. Bactérias, fungos, cistos de protozoários e ovos de helmintos podem ficar fisicamente aderidos ao corpo das formigas, sendo carreados de um ambiente a outro sem dificuldade.

Ainda que estudos elucidem o potencial de vetoração de helmintos a humanos, por formigas e outros insetos, raros são os que mencionam o papel destes na vetoração em ambiente de cativeiro, como canis, gatis e zoológicos. Assim, este trabalho teve o objetivo de verificar o potencial mirmecológico na vetoração mecânica de helmintos em um gatil particular localizado no Município de Matias Barbosa, MG.

O gatil é composto por cinco recintos onde se distribuem 60 gatos, machos e fêmeas, sem raça definida, castrados e de diferentes idades, sendo a maioria recolhida ao gatil quando filhote. Os animais têm água e ração ad libitum e cada recinto é formado por uma área interna de $9 \mathrm{~m}^{2}$, com alimento, água e áreas de descanso. Há também uma área externa de $60 \mathrm{~m}^{2}$, onde os animais passam grande parte do tempo e eliminam suas fezes e urina. No momento do estudo os animais estavam com a vermifugação a ser realizada e assim que terminado o estudo, esse procedimento foi efetuada pelo veterinário responsável. Este trabalho foi aprovado pelo Comitê de Ética da Universidade Federal de Juiz de Fora sob o número de Registro 025/2009.

Recebido em 6 de maio de 2010 
Para o presente estudo, em cada um dos cinco recintos, foram coletadas formigas sobre as fezes e ração, bem como amostras fecais. Em cada um dos cinco dias de coleta, foram capturadas formigas, de 10 em 10 minutos durante uma hora, sobre a ração e fezes e colhidas cerca de $2 g$ de fezes por recinto.

As formigas encontradas sobre as fezes e alimento, foram coletadas com pincel e acondicionadas em microtubos tipo Eppendorf contendo $2 \mathrm{~mL}$ de água destilada e etiquetado com data, recinto e local de coleta (fezes ou alimento). As fezes, colocadas em potes plásticos, foram transportadas em caixas térmicas até o laboratório. No mesmo dia de coleta, foi feita a técnica de sedimentação simples (Hoffmann) para avaliação das fezes. O material foi deixado para sedimentação de um dia para o outro e no dia seguinte analisaram-se, sob microscópio ótico, quatro lâminas por amostra de fezes. Também em laboratório, o Eppenddorf contendo água destilada e formigas foi agitado vigorosamente segundo técnica proposta por Thyssen et al. (2004). As formigas, retiradas para identificação até o gênero, foram acondicionadas em potes com álcool $70 \%$ e a água onde se encontravam foi centrifugada por dois minutos. A água foi observada sob microscópio óptico, sendo duas lâminas para cada Eppendorf. As técnicas utilizadas seguiram o padrão de Thyssen et al. (2004) para a análise das formigas e Dryden et al. (2005) para a análise das fezes. Para a identificação, os ovos foram medidos com régua acoplada à ocular do microscópio ótico, analisados quanto às características externas e, quando necessário, um manual fotográfico foi utilizado.

Os gêneros de formigas coletadas sobre as fezes e alimento dos gatos foram: Procryptocerus, Paratrechina, Pheidole e Iridomyrmex. Cruzando os resultados da análise das fezes e de alimento com os resultados da análise da água onde as formigas haviam sido armazenadas, verificou-se que as dos gêneros Pheidole e Paratrechina podem ser potenciais vetores de ovos de nematóides, em especial da ordem Ascaridida, família Toxocaridae (Fig. 1A e 1B), comumente encontrada nas fezes de felinos domésticos em estudos parasitológicos. Oliveira e Campos-Farinha (2005) demonstraram que ao menos a espécie Pheidole aberrans pode ser considerada uma praga urbana, amplamente disseminada em áreas domiciliares e, tendo em vista o resultado aqui encontrado, o controle de tal espécie é de grande interesse a fim de reduzir a dispersão de helmintos de importância sanitária. Também o gênero Paratrechina possui o mesmo papel de Pheidole sendo classificada como praga urbana (Solis et al., 2007), capaz de carrear parasitos neste ambiente. Este gênero pode carrear bactérias importantes como Acinetobacter, Streptococcus, Gemella, e Klebsiella (Moreira et al., 2005). Villani et al. (2008) evidenciaram o papel das espécies Camponotus rufipes, Solenopsis saevissima e Acromyrmex niger na vetoração de ovos de Ascaris lumbricoides comprovando a importância médica dessas espécies de formigas com status praga.
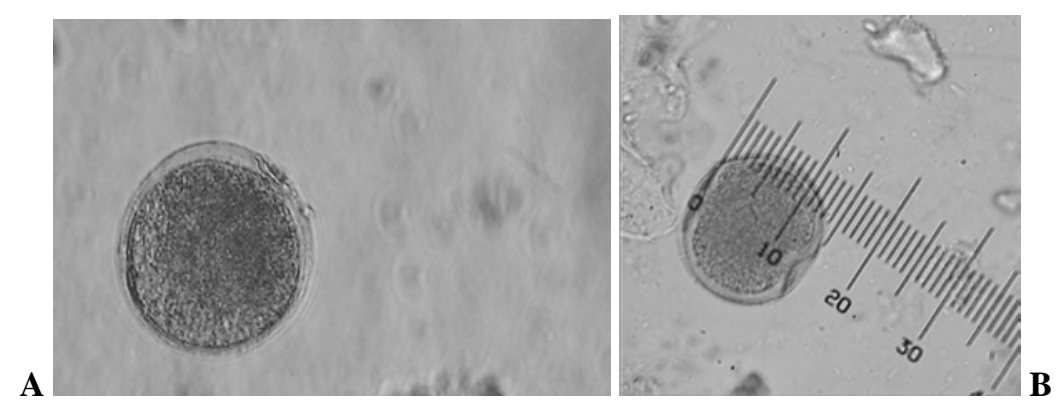

Figura 1. A. Ovo de Toxocaridae encontrado no corpo de uma formiga coletada no estudo. B. Ovo de Toxocaridade encontrado nas fezes

O presente trabalho alerta para o risco que espécies comuns de formigas urbanas podem representar para animais em cativeiro, principalmente pelo fato de a ração desses animais ser atrativa para formigas. $\mathrm{O}$ enfoque dessa temática tem sido raro quando se trata da 
importância veterinária de tais insetos. Atentar para a possibilidade de carreamento mecânico por formigas nesse ambiente pode colaborar para a saúde dos animais cativos, domésticos ou não, e do homem que lida com tais indivíduos.

Palavras-chave: formiga, gato, parasito, vetor

\begin{abstract}
Vector potential of ants in mechanic dissemination of helminthes in a cat rescue center was analyzed in this study. Ants walking over cat's food and feces were collected and conditioned in distilled water. Cat feces were collected too. Ants were identified and the water where they were conditioned was observed on optic microscope. It was made the simple sedimentation technique to analyze feces. The results show that ants species Pheidole and Paratrechina can be potential vectors of nematode eggs, mainly Ascaridida, Toxocaridae.
\end{abstract}

Keywords: ant, cat, parasites, vector

\section{AGRADECIMENTOS}

Os autores agradecem à proprietária do gatil Maria José Ribeiro Toledo por permitir o desenvolvimento desta pesquisa em sua propriedade. Agradecem ainda à Prof. Msc. Sueli de Souza Lima, Dr ${ }^{\mathrm{a}}$ Elisabeth de Almeida Bessa, Dr. Adriano Reder de Carvalho e Prof. Msc. Fabiano Matos Vieira por autorizarem o uso do laboratório de helmintologia da Universidade Federal de Juiz de Fora, MG, e por colaborarem nas dúvidas sobre parasitologia.

\section{REFERÊNCIAS BIBLIOGRÁFICAS}

ASH, N.; GREENBERG, B. Vector potential of the German cockroach (Dictyoptera: Blattellidae) in dissemination of Salmonella enteritidis serotype Typhimurium. J. Med. Entomol., v.17, p.417-423, 1980.

DRYDEN, M.W.; PAYNE, P.A.; RIDLEY, R. et al. Comparison of common fecal flotation techniques for the recovery of parasite eggs and oocysts. Vet. Therap., v.6, p.50-55, 2005.

FOTEDAR, R.; BANERJEE, U. Nosocomial fungal infections - study of the possible role of cockroaches (Blattella germanica) as vectors. Acta Trop., v.50, p.339-343, 1992.

IMAMURA, S.; KITA, M.; YAMAOKA, Y. et al. Vector potential of cockroaches for Helicobacter pylori infection. Am. J. Gastroenterol., v.98, p.1500-1503, 2003.

MOREIRA, D.D.O.; DE MORAIS, V.; VIEIRADA-MOTTA, O. et al. Ants as carriers of antibiotic-resistant bacteria in hospitals. Neotrop. Entomol., v.34, p.999-1006, 2005.
OLIVEIRA, V.C.; MELLO, R.P.; D'ALMEIDA, J.M. Dípteros muscóides como vetores mecânicos de ovos de helmintos em jardim zoológico. Ver. Saúde Pública, v.36, p.614-620, 2002.

OLIVEIRA, M.F.; CAMPOS-FARINHA, A.E.C. Formigas Urbanas do Município de Maringá-PR e suas Implicações. Arq. Inst. Biol., v.72, p.33-39, 2005.

SCHÜLLER, L. Microorganismos patogênicos veiculados por "formigas andarilhas" em unidades de alimentação. 2004. 120f. Dissertação (de Mestrado em Saúde Pública). Faculdade de Saúde Pública Universidade de São Paulo, São Paulo.

SOLIS, D.R.; BUENO, O.C.; MORETTI, T.C. et al. Observações sobre a biologia da formiga invasora Paratrechina longicornis Latreille, 1802)(Hymenoptera, Formicidae) em ambiente urbano brasileiro. Rev. Bras. Zoocienc.,v.9, p.7580, 2007.

THYSSEN, P.J.; MORETTI, T.C.; UETA, M. T. et al. O papel de insetos (Blattodea, Diptera e Hymenoptera) como possíveis vetores mecânicos de helmintos em ambiente domiciliar e peridomiciliar. Cad. Saúde Pública, v.20, p.10961102, 2004.

VILLANI, F.; MORINI, M.S.C.; FRANCO, M.A. et al. Evaluation of the possible role of ants (Hymenoptera: Formicidae) as mechanical vectors of nematodes and protists. Braz. Arch. Biol. Technol., v.51, p.923-928, 2008.

ZARZUELA, M.F.M.; RIBEIRO M.C.C.; CAMPOS-FARINHA, A.E.C. Distribuição de formigas urbanas em um hospital da Região Sudeste do Brasil. Arq. Inst. Biol., v.69, p.85-87, 2002. 